\title{
ANÁLISE CRÍTICA: "INSUFICIÊNCIA" TEÓRICO-CONCEITUAL DOS DIREITOS FUNDAMENTAIS SOCIAIS ${ }^{1}$
}

\author{
CRITICAL ANALYSIS: THE THEORETICAL AND CONCEPTUAL FAILURE OF FUNDAMENTAL
} SOCIAL RIGHTS

\section{Marco Aurélio Serau Junior"}

\begin{abstract}
Resumo:
O presente texto se propõe a examinar de maneira crítica a insuficiência teóricoconceitual que envolve o estudo dos direitos fundamentais econômicos, sociais e culturais, a qual contribui apenas para seu enfraquecimento e dificulta sua concretização.

A superação desse déficit dogmático implica em que se reveja conceitos como a equiparação dos direitos sociais a meras prestações estatais ou simples gastos governamentais, escapando-se da armadilha neoliberal; a percepção da identidade substancial entre direitos de "primeira" e "segunda" geração/dimensão; o reconhecimento da eficácia horizontal dos direitos fundamentais; a rejeição da tese da inexigibilidade dos direitos sociais em razão de sua imprecisão de conteúdo.

Palavras-Chave: Direitos Sociais. Conceito. Insuficiência. Efetividade.

Abstract:

This current text intent to examine in a critical way the theoretical and conceptual failure that involves the study of fundamental economic, social and cultural rights, which only contributes to their weakening and difficult their achievement.

Overcoming this deficit dogmatic implies reconsidering concepts such as equal social rights to state benefits or merely cost governments, escaping from neo-liberal trap; the identity substantial perception between the rights of "first" and "second" generation/ dimension, the recognition of horizontal fundamental rights effectiveness and rejection of the thesis of not required of social rights due to their inaccuracy of content.
\end{abstract}

Keywords: Social rights. Concept. Insufficiency. Effectiveness.

Introdução

A rápida leitura do título do presente trabalho poderia conferir ao leitor uma falsa idéia da pretensão ora esposada. Com efeito, poder-se-ia pensar em mais um

\footnotetext{
Artigo adaptado de trabalho produzido para a disciplina "Teoria Geral dos Direitos Fundamentais", ministrada pelo Exmo. Sr. Prof. Fábio Konder Comparato, na pós-graduação em Direitos Humanos da Faculdade de Direito da Universidade de São Paulo.

Doutor em Direitos Humanos pela Faculdade de Direito da Universidade de São Paulo. Especialista em Direitos Humanos Faculdade de Direito da Universidade de São Paulo. Especialista em Direito Constitucional (Escola Superior de Direito Constitucional). Professor de cursos de pós-graduação, na área de Direito Previdenciário. Assessor no Tribunal Regional Federal da $3^{\text {a }}$ Região. maseraujunior@hotmail. com.
} 
trabalho, como tantos outros, meramente dogmático, de índole conservadora e instruído com o escopo de negar vigência e aplicabilidade aos direitos sociais e econômicos.

Entretanto, o objetivo do presente escorço intelectual é justamente o oposto. Buscando discutir brevemente algumas lacunas ou insuficiências teórico-conceituais que são objeto de nossas reflexões a respeito dos direitos econômicos e sociais, o que se pretende é, ao revés, buscar supri-las e robustecer o próprio conceito e a teoria dos direitos sociais, com o conseqüente fortalecimento da prática e da eficácia destes. Segundo Comparato, "a grande tarefa atual dos profissionais do direito, nessa matéria, consiste em construir tecnicamente garantias públicas, adequadas à realização desses direitos" (2005, p. 336-337).

Nesse sentido, uma robusta Teoria dos Direitos Sociais poderia colaborar à superação de idéias falaciosas e amplamente aceitas na dogmática jurídica tais como a da "reserva do possível" o caráter meramente programático dos direitos sociais e econômicos, dentre outras.

Em síntese, o que se pretende dizer é que, superada a insuficiência conceitual dos direitos fundamentais sociais, talvez se combata mais firmemente esse núcleo de idéias conservadoras que busca retirar por completo a eficácia das normas de Direito Social.

Alguns ramos do Direito, eminentemente jungidos na tradição milenar do Direito Privado, são apresentados ao operador do Direito como dotados de um esboço conceitual bastante robusto, praticamente inquestionável. Assim, ao falarmos em direitos reais, direito de propriedade, posse, negócio jurídico, contrato, etc., vêm à mente sólidas instituições jurídicas e conceitos teóricos praticamente inabaláveis quanto à sua operacionalidade, exigibilidade, etc. ${ }^{2}$

Todavia, o mesmo já não se pode afirmar quanto aos direitos econômicos e sociais, os quais ainda padecem de duras críticas quanto à sua existência, sua eficácia, sua exigibilidade jurídica e judicial e principalmente no que concerne à sua concreção (efetividade dos direitos previstos em norma escrita).

2 A certeza a respeito de alguns conceitos de Direito Privado e a alegada segurança jurídica deles advinda não passa de mera retórica. A análise dos principais autores de tal disciplina nos revela incongruências e divergências inconciliáveis, ainda que muitas vezes cheguem às filigranas jurídicas. Veja-se, à guisa de exemplo, a divergência teórica sobre o conceito jurídico de posse existente nas obras de Savigny e Ihering. No mesmo sentido, e agora já esmiuçando um pouco a doutrina jurídica pátria, pode-se escolher qualquer outro instituto jurídico de Direito Privado e analisar as obras de autores clássicos como Pontes de Miranda, Clóvis Bevilacqua, Teixeira de Freitas que certamente serão encontradas diferenças teóricoconceituais. Todavia, no caso dos institutos de Direito Privado, em nenhum momento os operadores do Direito, deparando-se com tal insuficiência conceitual (melhor dizendo: ausência de conceitos jurídicos universalmente aceitos) hesita em aplicá-los, deixando de lhes dar concreção. Isto, porém, não ocorre quanto aos direitos sociais, o que pensamos que aconteça muito mais por opção ideológica que por insuficiência teórico-conceitual. 
Procurarei defender, nesse trabalho, que a negativa de vigência aos direitos sociais possui muito de ideológico, visto que às classes dominantes, mormente num sistema capitalista de produção econômica, não interessa promover justiça social e reduzir as desigualdades, assegurando o ideal de dignidade da pessoa humana.

Contudo, além desse fator, cremos que a pouca eficácia dos direitos sociais também se deve à sua insuficiência teórico-conceitual, ou um déficit dogmático (BONAVIDES, 2003, p. 595). Os pensadores do Direito ainda não encontraram muito êxito na construção de uma robusta teoria dos direitos fundamentais sociais. Com efeito, não se pode olvidar que os militantes de direitos humanos lutaram e têm lutado pela concreta implementação dos direitos fundamentais sociais. Porém, no campo teórico, muitas lacunas se fazem presentes e, a meu ver, enfraquecem muitos dos argumentos utilizados na defesa dos direitos sociais (e, conseqüentemente, o próprio caminho de sua efetivação).

Um dos principais pontos de crítica a ser efetuado diz respeito à equiparação ou redução dos direitos fundamentais sociais a meros direitos de classe ou simples atividades estatais prestacionais. É certo que tais elementos estão intimamente vinculados à própria origem e concepção dos direitos fundamentais sociais, mas estes não se restringem a tanto, possuindo dimensão muito mais ampla, tanto conceitual e normativa como concretamente.

Tal falha conceitual colabora a retirar a força dos direitos sociais, que seguem sendo uma boa causa destituída de bons argumentos. Reduzidos os direitos sociais a direitos de classe, estes se enfraquecem na medida em que vivemos uma fase de reestruturação do sistema capitalista que está a ponto de prescindir do próprio trabalho, centrando-se no capital (COMPARATO, 2005, p. 65).

Por outro lado, resumidos os direitos sociais a meras atividades estatais de prestação - desvinculadas de um arranjo ou rearranjo social - fica-se preso à armadilha posta pelas teorias neoliberais de redução do Estado (responsabilidade fiscal, governabilidade econômica, etc.), com notável prejuízo à defesa e concretização dos direitos sociais.

Diante destas preocupações, e de outras que serão delineadas no presente trabalho, acredito que uma concepção teórica mais robusta auxiliaria na árdua tarefa de concretização dos direitos fundamentais sociais e o presente trabalho segue, portanto, nessa seara, na tentativa de lançar algumas luzes sobre o assunto.

\section{Breve evolução dos direitos fundamentais}

A brevidade do presente trabalho afasta a possibilidade de se dissertar longamente sobre a evolução dos direitos humanos, e sua progressão dos ditos direitos fundamentais de primeira geração para os direitos fundamentais de segunda geração, locus jurídico onde se encaixam os direitos sociais e econômicos (lembrando-se, ademais, da 
existência de direitos ditos de terceira ou quarta geração, conforme: Bonavides (2003, p. 569-574).

Entretanto, e ainda atentos a essa necessidade de brevidade, não se pode deixar de mencionar que o curso histórico dos direitos humanos é o desenrolar de lutas no sentido de, progressivamente, assegurar-se a plena garantia e proteção da dignidade da pessoa humana. Paralelamente a essas lutas desenvolvidas no campo social e político, a afirmação plena dos direitos humanos sempre se valeu do progressivo arranjo de um instrumental jurídico apto a corroborar as conquistas culturais e políticas nesse campo ou, segundo Comparato, "instituições jurídicas de defesa da dignidade humana contra a violência, o aviltamento, a exploração e a miséria" (2005, p. 01).

$\mathrm{E}$ as primeiras instituições jurídicas efetivamente desenvolvidas contra o arbítrio se articularam num sentido de opor amarras ao Poder Público, traduzindo-se num certo absenteísmo estatal (liberdades clássicas; liberdades negativas).

Todavia, dentro do sistema capitalista que se desenvolveu fortemente a partir do quadro jurídico traduzido pela expressão Constitucionalismo Liberal, apareceram gritantes e desumanas contradições sociais, as quais apontaram novas formas de opressão e mesmo supressão da dignidade humana:

[...] em contrapartida a essa ascensão do indivíduo na História, a perda da proteção familiar, estamental ou religiosa tornou-o muito mais vulnerável às vicissitudes da vida. A sociedade liberal ofereceu-lhe, em troca, a segurança da legalidade, com a garantia da igualdade de todos perante a lei. Mas essa isonomia cedo revelouse uma pomposa inutilidade para a legião crescente de trabalhadores, compelidos a se empregarem nas empresas capitalistas. Patrões e operários eram considerados, pela majestade da lei, como contratantes perfeitamente iguais em direitos, com inteira liberdade para estipular o salário e as demais condições de trabalho. Fora da relação de emprego assalariado, a lei assegurava imparcialmente a todos, ricos e pobres, jovens e anciãos, homens e mulheres, a possibilidade jurídica de prover livremente à sua subsistência e enfrentar as adversidades da vida, mediante um comportamento disciplinado e o hábito da poupança.

O resultado dessa atomização social, como não poderia deixar de ser, foi a brutal pauperização das massas proletárias, já na primeira metade do século XIX (COMPARATO, 2005, p. 52-53).

Assim, novas demandas sociais se impuseram, derivando disso modificação no teor da proteção à dignidade da pessoa humana. Diante disso, a esfera jurídica de proteção à dignidade da pessoa humana migra, paulatinamente, da sociedade civil para o Estado, com a criação progressiva de aparatos estatais de Seguridade Social, envolvendo, 
de modo geral, a atuação nas áreas de Saúde, Previdência Social e Assistência Social (CESARINO JR., 1970, p. 48-54; CORREIA, 2001, p. 01-11), bem como a previsão de mecanismos jurídicos de intervenção estatal na área econômica (criação do Direito do Trabalho; novos moldes para o Direito Administrativo etc). Com efeito, realmente os direitos sociais, num primeiro estágio, implicaram ou se identificaram com atividades estatais prestacionais (liberdades positivas, condutas estatais comissivas).

O primeiro momento em que os direitos sociais e econômicos são alçados ao patamar de norma constitucional (o que é de extrema relevância dada a prevalência, no mundo moderno, de sistemas jurídicos de feição estritamente positivista) ocorre com a promulgação da Constituição Mexicana de 1917, ainda antes dessa discussão encontrarse pacificada na Europa, e antes também dos Estados Unidos, onde ainda se objeta a dimensão social dos direitos humanos (COMPARATO, 2005, p. 174). Seguiu-se à Carta Mexicana a Constituição alemã de Weimar, de 1919, sendo que, posteriormente, a constitucionalização dos direitos sociais e econômicos ganhou mundo e se alastrou por outros continentes e outros Textos Constitucionais.

2. A redução dos direitos sociais a simples atividades estatais

Para que seja implementado um efetivo Sistema de Direitos Humanos, necessário se faz consolidar tais conceitos, investigando sua substância e núcleo, a fim de que se possa melhor operacionalizá-los, propiciando, destarte, melhores condições de exigibilidade judicial, de postulação de políticas públicas, de reconhecimento pela sociedade civil, etc.

Nesse rumo, é de se reconhecer que os direitos sociais e econômicos não são diferenciados dos direitos individuais (se é que realmente apresentam alguma diferença ontológica em relação a estes, como será discutido adiante) simplesmente por existirem como atividades estatais veiculados em norma jurídica - no geral normas jurídicas de primeiro escalão.

A lógica empregada a respeito de direitos sociais deve ser invertida, verificando-se que tais direitos são consagrados no Direito Positivo como forma de atendimento a diversas necessidades básicas inerentes à garantia de dignidade da pessoa humana. Da constatação da necessidade humana é que se chega à construção da norma jurídica: os direitos fundamentais sociais não são exatamente direitos apenas prestacionais, mas, mais precisamente direitos de resposta - resposta ao flagelo social - ou, como se consagrou na expressão clássica freedom from want, freedom for fear.

O Estado deve organizar-se de modo que preveja uma ampla rede de proteção social, eis que todos os cidadãos - ou a maior parte deles, no sistema capitalista - encontram-se sujeitos às vicissitudes naturais (tais como a doença, a incapacidade para 
o trabalho, morte de quem lhe provê o sustento, o impedimento para o trabalho em razão de gestação, etc.).

A inexistência de normas jurídicas que previssem tais direitos não thes retiraria sua jusfundamentalidade dentro do ordenamento jurídico, justamente considerando a necessidade de preservação da dignidade humana e o importante papel desse núcleo de direitos para a consecução desse objetivo (COMPARATO, 2005, p. 57-59).

A concepção de um Estado prestacional (Estado-Providência), não é a essência, mas sim a conseqüência da vinculação dos direitos de ordem social à dignidade da pessoa humana. Com efeito, o Estado só assumiu o papel de prestador de algumas atividades de proteção à dignidade humana e garantia do mínimo vital dada a passagem da sociedade Ocidental para o Capitalismo e a conseqüente insuficiência da rede privada de proteção social (CANÇADO TRINDADE, 2003, p. 487). Todavia, ressalte-se, esse não é, nem pode ser o núcleo dos direitos fundamentais sociais, dado que a prestação de tais atividades pode ser rearranjadas e, em certa, até já voltaram a ser exercidas pela sociedade civil, conforme teremos oportunidade de expor adiante, e, desde que não haja efetivo prejuízo à dignidade humana, mal algum reside nisso.

Ademais, atualmente se discute a chamada eficácia horizontal dos direitos humanos (em contraposição à eficácia vertical, que é aquela que diz respeito às relações entre Estado e sociedade civil), que quer dizer o respeito aos direitos humanos, e sua eficácia vinculativa não apenas referente ao Estado, mas também por entidades privadas, chegando-se ao que a doutrina alemã denomina de "proteção da liberdade pessoal contra o exercício de poder econômico ou social" (HESSE, 1998, p. 285-286). Segundo leciona Konrad HESSE: "liberdade humana é posta em perigo não só pelo Estado, mas também por poderes não-estatais, que na atualidade podem ficar mais ameaçadores do que as ameaças do Estado" (1998, p. 278). ${ }^{3}$

Por outro lado, os direitos fundamentais sociais não aceitam qualquer forma de efetivação. Estes devem ser concretizados de acordo com outros princípios nucleares dos direitos humanos, tais como a liberdade, o pluralismo político-ideológico e a participação democrática. A idéia é que sua efetivação seja não-autoritária, sequer estatizante, mas, ao revés, aberta à promoção pelos próprios interessados e às iniciativas da sociedade civil.

Como defende Jorge Miranda (2000, p. 389-390):

Na Constituição portuguesa, singular entre suas similares, há a previsão expressa da vinculação das entidades privadas aos direitos fundamentais (art. 18, n. 01). A modernidade do texto constitucional português é evidente, à medida que atualmente, muitas transnacionais cometem severos delitos contra os direitos humanos, inclusive de ordem social. Exemplificando, podemos noticiar a exploração massiva de trabalho infantil por empresas transnacionais; o desenvolvimento de pesquisa tecnológico-farmacêutica com verdadeiras "cobaias-humanas" oriundas dos países mais pobres, etc. 


\begin{abstract}
Não se trata apenas de criar serviços ou concretizar prestações, pecuniárias ou outras; trata-se também, por um lado, de dar lugar e voz aos destinatários e beneficiários segundo a Constituição e a lei e, por outro lado, de admitir formas de complementaridade ou de concorrência entre as intervenções do Estado e das demais entidades públicas e as iniciativas das pessoas e dos grupos existentes na sociedade civil.
\end{abstract}

Mais eficaz para a promoção e garantia dos direitos sociais seria aproximálos da idéia nuclear da proteção à dignidade da pessoa humana (ainda que em alguns casos sua operacionalização seja diferenciada, o que também não é integralmente verdadeiro, conforme demonstraremos ao longo deste trabalho). A plena vigência dos direitos sociais só ocorrerá quando toda a sociedade estiver envolvida com essa disciplina.

Não se propugna simplesmente um retorno à proteção social "privada" a qual pode ser insuficiente no parâmetro capitalista. A idéia é buscar formas realmente efetivas e eficazes de proteção social, com envolvimento de toda a sociedade e com o abandono da idéia de dicotomia entre Estado e sociedade civil.

Nesse sentido, deve-se buscar levar à sociedade a idéia do dever fundamental de solidariedade, em certos casos já bem delineado no ordenamento jurídico brasileiro. Veja-se, por exemplo, o princípio da solidariedade social, norteador da Seguridade Social (Saúde, Previdência e Assistência Social), segundo o qual aqueles que podem contribuem no limite de suas forças para estruturar-se a proteção social, inclusive para aqueles que não podem contribuir de modo algum. ${ }^{4}$

A noção de solidariedade é componente fundamental dos direitos fundamentais sociais. Segundo Comparato:

A solidariedade prende-se à idéia de responsabilidade de todos pelas carências ou necessidades de qualquer indivíduo ou grupo social. É a transposição, no plano da sociedade política, da obligatio in solidum do direito privado romano. O fundamento ético desse princípio encontra-se na idéia de justiça distributiva, entendida como a necessária compensação de bens e vantagens entre as classes sociais, com a socialização dos riscos normais da existência humana (2005, p. 64)

Com efeito, os direitos sociais seriam encarados à guisa de obrigações coletivas, não meramente prestações estatais/gastos públicos, e com isso se encontrariam muito mais fortalecidos em sua juridicidade.

\footnotetext{
4 A relação de custeio da Seguridade Social não pode ser pensada exclusivamente em termos de relação jurídico-tributária, embora esteja estruturada nestes termos; deve prevalecer a finalidade especifica da Seguridade e sua estruturação de acordo com a idéia de solidariedade social.
} 
3. A inexistência de diferenças teórico-conceituais significativas entre direitos de primeira e segunda geração

Não há diferença substancial de ordem teórica ou conceitual entre direitos de "primeira geração" - direitos civis e políticos - e aqueles ditos de "segunda geração" - onde podemos encaixar os direitos sociais e econômicos, visto que ambos os regimes jurídicos vinculam-se e ancoram sua fundamentalidade na idéia de proteção à dignidade da pessoa humana.

Os direitos ditos de primeira geração também demandam, para sua implementação e concretização, o desenvolvimento de políticas públicas e gastos estatais (MIRANDA, 2000, p. 108-109). Com efeito, a organização de eleições livres e desembaraçadas, pilar da democracia (direitos políticos), demanda vultosos gastos públicos. No mesmo sentido, por exemplo, a orientação e execução de políticas de segurança pública, idôneas a tutelar os direitos à propriedade, à vida e à liberdade (direitos civis), os quais demandam igualmente pesados dispêndios por parte do Estado.

Mesmo diante deste quadro nunca se questionou a validade ou existência jurídica dos direitos de primeira geração, o que comumente se aventa contra os direitos sociais e econômicos, a fim de obstar ou retardar sua efetiva implementação.

Nessa mesma linha de raciocínio, de se destacar que os direitos humanos demandam, para sua concretização, organização e procedimento, indistintamente sejam direitos individuais ou direitos sociais (HESSE, 1998, p. 287-288; BONAVIDES, 2003, p. 565-569).

O que se pretende com tal ordem de argumentação é afastar argumentos falaciosos como a idéia de "reserva do possivel", isto é, a implementação dos direitos sociais e econômicos ocorrendo apenas na medida das forças econômicas do Estado. Ao mesmo passo, identificando-se a inexistência de efetiva diferença ontológica entre direitos de primeira e segunda geração, talvez encontre-se argumentos para consolidar uma melhor proteção judicial dos mesmos.

Por derradeiro, é de se destacar que, segundo dispõe a Convenção de Viena, de 1993, os direitos humanos são universais, indivisíveis, interdependentes e inter-relacionados (no mesmo sentido: CANÇADO TRINDADE, 2003, p. 488). Assim, se o fundamento último dos direitos humanos é a idéia de dignidade da pessoa humana, não se pode conceber uma atuação relativa a direitos fundamentais que bidimensione-os, bipartindo-os em direitos civis e políticos e direitos sociais e econômicos. Tais dimensões não são estanques, sequer incomunicáveis. Ao revés, são indissociáveis, nos termos bem lançados por aquela Conferência. Como diz Jorge Miranda:

A existência das pessoas é afectada tanto por uns como por outros direitos. Mas em planos diversos: com os direitos, liberdades e garantias, é a sua esfera de autodeterminação 
e expansão que fica assegurada, com os direitos sociais é o desenvolvimento de todas as suas potencialidades que se pretende alcançar; com os primeiros, é a vida imediata que se defende do arbítrio do poder, com os segundos é a esperança numa vida melhor que se afirma; com uns, é a liberdade actual que se garante, com os outros é uma liberdade mais ampla e efectiva que se começa a realizar (2000, p. 105)

Embora os diferentes grupos de direitos se refiram a planos diversos, como aparece com nitidez na lapidar lição transcrita, é certo que suas diferenças não vão além, pois sempre se busca a proteção e o resguardo da dignidade da pessoa humana. Como diz a doutrina, direitos individuais e direitos sociais não possuem diferenças no seu cerne estrutural, mas, no máximo, são suscetíveis de regimes jurídicos diferenciados (MIRANDA, 2000, p. 99) ou diferenças quanto à sua titularidade. Todavia, a diferença eventual de regimes jurídicos não autoriza seja negada sua força normativa (BONAVIDES, 2003, p. 647).

Com efeito, os direitos humanos possuem a característica da universalidade, isto é, são aplicáveis, atribuíveis, inerentes e exigíveis por todo e qualquer ser humano. Entretanto, a fim de que se possa atender a necessidades específicas desse ou daquele grupo social (ou mesmo qualquer outra forma de aglutinação de necessidades sociais em torno de pessoas ou sujeitos históricos), surgiram historicamente (e surgirão outros grupos normativos, visto que a própria história dos direitos humanos é a progressividade constante) alguns blocos normativos que correspondem a direitos fundamentais com destinatários certos ou, ao menos, determináveis. O magistério de Miranda (2000, p. 8485) mais uma vez clarifica o que se encontra nebuloso:

Os direitos fundamentais sobrevieram, pois, como direitos do homem e de todos os homens. Havia e há, porém, na sociedade, múltiplos estados e situações em que as pessoas se encontram integradas, susceptíveis de as qualificar ou de para elas implicarem identidades particulares. A época liberal terá conseguido ignorá-las ou pô-las em causa, não pôde fazer que não existissem; e a vida dos nossos dias mostrou-as mais nítidas, fez avultar diferentes grupos e formulou (ou formulou de novo), sob a sua influência, muita da protecção constitucional dos indivíduos.

Daí a necessidade, hoje, de distinguir entre direitos comuns ou universais dos cidadãos e direitos particulares ou direitos próprios destes ou daqueles cidadãos; de distinguir entre direitos de todos os membros da comunidade política, só por virtude dessa qualidade, e direitos de certos e determinados membros, devido às categorias sociais que integram ou às situações duradouras em que tenham de se mover. 
Por derradeiro, de se anotar que a doutrina identifica, para os direitos fundamentais, após a vigência do Estado Social, certa estrutura comum, aplicável indistintamente sejam classificados como direitos humanos de primeira ou segunda geração: diversificação do catálogo, para além das declarações clássicas de direitos fundamentais; irradiação para todos os ramos do Direito; reconhecimento da conexão com garantias institucionais; consideração do homem situado, traduzida na relevância dos grupos e das pessoas coletivas; reconhecimento da complexidade de estrutura de muitos direitos fundamentais; dimensão plural e poligonal das relações jurídicas; produção de efeitos não só verticais (frente ao Estado), mas igualmente horizontais (entre particulares); dimensão participativa e procedimental dos direitos humanos; interferência dos direitos humanos não só quanto ao legislador, mas também em relação à Administração e Judiciário, quanto à sua concretização (MIRANDA, 2000, p. 32).

4. Inexatidão da equiparação dos direitos fundamentais sociais a meros "gastos públicos"

Outro fator que comumente é atribuído ao conceito de direitos fundamentais sociais, e que a meu ver somente contribui para o enfraquecimento de sua força normativa é a sua assimilação, pela doutrina, simplesmente a "gastos públicos"

Com efeito, em sua origem, no início do século XX, os direitos sociais e econômicos realmente possuíam essência muito ligada à idéia de simples gastos públicos derivados de prestações estatais. Todavia, sua conformação atual, até pelo maior grau de complexidade que a sociedade vivencia, não pode se resumir a tanto, sob pena de enfraquecimento mesmo do próprio núcleo desses direitos fundamentais.

Muitos direitos sociais implicam vultosos gastos públicos. Todavia, nem sempre essa é uma relação necessária. $\mathrm{O}$ argumento é falacioso e somente gera descompromisso para com a causa dos direitos humanos, pois igualar direitos fundamentais a "despesas públicas" facilita a pressão - até mesmo popular - no sentido de reduzilos, visto que representariam não a proteção a aspectos da dignidade humana, mas meros gastos oriundos do Poder Público.

Veremos, pois, algumas dessas situações em que direitos sociais não se equiparam por completo a gastos públicos. A começar, um exemplo bem atual e bastante presente nas discussões mais atuais de Direitos Humanos: a questão da inclusão social e as políticas de cotas.

Com efeito, as políticas de cotas, embora assim se divulgue em muitos veículos de comunicação, não representam em hipótese alguma aumento de gastos estatais. Por certo o que ela opera é, nada mais nada menos, do que uma redistribuição de posições sociais, pormenorizando a idéia maior de redistribuição de justiça (justiça distributiva). As mesmas vagas já existentes em Universidades Públicas (portanto, os mesmos e já previstos 
gastos públicos) são apenas destinadas a outrem que não aqueles privilegiados e filhos das elites privilegiadas que sempre monopolizaram o ensino superior gratuito em nosso país.

De outra feita, há direitos fundamentais tipicamente de ordem socialeconômica para cuja implementação e garantia não se demandam maiores gastos públicos que aqueles que normalmente devem ser efetuados para a tutela dos direitos de primeira geração. Ou, sob outro prisma, demandam apenas atividade meramente fiscalizatória ou regulamentar, com o que não se verifica qualquer distinção conceitual em relação ao Estado-Gendarme típico do liberalismo político.

Tomando-se o exemplo dos Direitos Humanos de proteção à relação de trabalho, pode-se mencionar as ações de fiscalização e as ações coletivas ajuizadas pelo Ministério Público do Trabalho no combate ao trabalho infantil e ao trabalho escravo, flagelos sociais ainda existentes em nosso país. Considerado tal exemplo, em nada se pode localizar um tipo de gasto público que seja distinto daquele efetuado na persecução criminal ou mesmo numa ação penal pública com o intuito de proteger a vida, a liberdade, e principalmente, a propriedade privada (pode mudar a forma de atuação, mas o conteúdo do ato é idêntico).

Atuando nessa linha meramente fiscalizatória e regulamentar o Poder Público não faz nada de novo em relação à sua forma de atuar já pré-existente, se considerarmos os direitos de primeira geração. Explicitada a falácia do argumento, roga-se que isso auxilia e contribua para uma melhor implementação dos direitos sociais.

Por derradeiro, e ainda a respeito da relação entre direitos fundamentais sociais e gastos públicos, é de se ter em conta que a responsabilidade na gestão de recursos públicos não pode ser levada a um ponto em que tal argumento sirva à supressão de direitos humanos. Ao revés, a assim chamada governabilidade deve ser conduzida a passos conjuntos e consentâneos aos direitos humanos. Veja-se o ímpar magistério de Canotilho:

Fica também claro que a 'good governance' não pode consistir numa simples política de alocação de recursos e de boas práticas orçamentais, se necessário autoritariamente impostas, com desprezo dos direitos fundamentais humanos e dos princípios basilares da democracia e do Estado de direito. Compreendem-se, assim, os esforços de uma significativa parte da doutrina na firma elevação dos direitos humanos e dos direitos fundamentais a pré-condição básica de qualquer boa governação contra as tentativas de, a partir de teorias de ingovernabilidade, legitimar uma qualquer 'metagovernação' ancorada na violência, na ideologia e nos interesses $(2005 \text {, p. } 332-333)^{5}$

s $O$ referido professor chega mesmo a indicar que a governabilidade deve, inclusive fazer parte da Teoria Constitucional, embora a limitação de sua participação na Ciência do Direito Constitucional seja restrita às rígidas balizas acima apontadas (CANOTILHO, 2005, p. 326). Nesse sentido, COMPARATO têm 
5. A inexigibilidade dos direitos fundamentais sociais em razão de sua imprecisão de conteúdo

Muito se alardeou a inexigibilidade dos direitos sociais e econômicos em razão de um suposto grau de indeterminação destes, comparados aos direitos individuais. E aqui mais uma vez a insuficiência teórico-conceitual relativa aos direitos fundamentais sociais é vislumbrada. Mas procuraremos delinear trilhas de luta idôneas a refutar tal ordem de argumentação.

Por primeiro, necessário se faz tratar da suposta certeza-segurança jurídica relativa aos direitos individuais. Com efeito, pouco após a Revolução Francesa, a época das codificações (cujo símbolo máximo é o Código Civil Francês) e a correlata ideologia burguesa-liberal inspiraram a idéia de que as liberdades civis (direitos individuais), tecnicamente configuradas através de arranjos normativos codificados - os Códigos propiciariam a existência de uma sociedade onde haveria total previsibilidade das condutas lícitas e das ações estatais, na medida em que tais condutas estivessem previstas nas leis escritas, estas concisas e acessíveis (GARCÍA DE ENTERRÍA, 2000, p. 35).

Porém, fatores como uma desenfreada inflação legislativa, somada à percepção plena da supremacia da Constituição (e dos valores de justiça trazidos pela Constituição) produziram (ou apenas explicitaram) a existência de insegurança jurídica e incerteza em relação ao conteúdo essencial dos direitos individuais, ocorrendo a superação daquele ideário positivista mais estreito (GARCÍA DE ENTERRÍA, 2000, p. 101-103).

Como se vê, diante do quanto narrado, também os direitos individuais já não mais possuem o mesmo grau de certeza e segurança jurídicas de sua feição seteoitocentista (se é que isso ocorreu, conforme demonstramos). Nestes termos, a alegação de incerteza conceitual relativa aos direitos fundamentais sociais não é idônea a obstar sua exigibilidade, pois, como se viu, também os direitos individuais estão a padecer de algum grau de incerteza e instabilidade.

Entretanto, ao invés de negar vigência a ambos os grupos normativos, a solução, tanto para a incerteza dos direitos individuais como dos direitos sociais - principalmente - é um gradativo e já verificável retorno à idéia dos princípios e da ponderação (assim como faziam os jurisconsultos romanos). Diante de um complexo normativo aparentemente desordenado, o mesmo deve ser re-ordenado através de princípios de justiça material: multitudo legum, unum ius (GARCÍA DE ENTERRÍA, 2000, p. 106-108; no mesmo sentido: ZAGREBELKSY, 1998).

desenvolvido linha de raciocínio no sentido de que uma gestão social dos orçamentos públicos (orçamentos participativos, orçamentos sociais) poderiam bem equalizar a gestão dos recursos públicos e o efetivo respeito aos direitos humanos. 
Expostos tais argumentos, verifica-se que qualquer repreensão aos direitos sociais com fulcro na idéia de sua imprecisão conceitual ou de sentido pode ser refutada com a adução da Teoria da Crise de Certeza do Direito, nos moldes expostos acima, com amparo nas lições de García de Enterría, crise essa que é solucionada através da utilização de princípios de justiça material, os quais possuem íntima ligação com os direitos humanos, mormente os de ordem social.

6. A superação da insuficiência teórico-conceitual dos direitos fundamentais sociais

Nos tópicos anteriores tivemos a oportunidade de verificar que os direitos fundamentais sociais não correspondem a meras previsões de gastos públicos, tampouco a "direitos prestacionais" ou simples atividades estatais. No mesmo sentido, examinou-se que são dotados de racionalidade jurídica, não se caracterizando, ademais, como meros "apelos ao legislador"

Cumpre, portanto, e a despeito da indivisibilidade e indissociabilidade dos direitos fundamentais, ao lado da inexistência de profundas divergências quanto a estrutura e regime jurídicos, apontar os indícios do que seja sua verdadeira natureza jurídica, seu núcleo fundamental.

Os direitos sociais, em geral, concretizam-se através de serviços e políticas públicas, ao passo que os direitos civis e políticos, na maior parte das vezes, consubstanciam-se em meros atos jurídicos, geralmente praticados de forma isolada. Isso sinaliza a grande diferença em termos de regime e teorias jurídicas aplicáveis. ${ }^{6}$

As formulações teóricas inerentes aos direitos fundamentais de primeira dimensão são apresentadas geralmente como se fossem universais e absolutas, o que não corresponde à verdade, pois há nisso forte componente ideológico (AZEVEDO, 1999).

Cumpre, então, tomar outra postura, buscando-se instrumental jurídico diverso (e adequado) para os direitos fundamentais de segunda dimensão, superando a apontada "insuficiência" teórico-conceitual. Assim como na parábola narrada pelo evangelista Marcos, em que se fala da necessidade de odres novos para vinho novo, sob pena de se perder o vinho e os odres, o mesmo sucede com os direitos econômicos, sociais

6 "Uma política pública não é um ato isolado nem, menos ainda, a abstenção de praticar determinados atos. Ela consiste numa atividade, conceito técnico elaborado pela mais recente teoria jurídica. Trata-se, com efeito, de uma série de atos, do mais variado tipo, unificados pela comunhão de escopo e organizados num programa de longo prazo. A doutrina jurídica tradicional, tanto nos países de civil law (Europa Continental e suas antigas colônias) quanto nos de common law (Inglaterra e suas antigas colônias), desde o direito romano, ocupou-se quase que exclusivamente de atos isolados: contratos, testamentos, matrimônio, adoção, nomeação e demissão de funcionários públicos, e assim por diante. Foi só recentemente, em razão do desenvolvimento da economia de massa, que começaram a ser elaboradas regras jurídicas específicas sobre o desenvolvimento de atividades, como a organização do serviço público, ou a exploração empresarial" (COMPARATO, 2005, p. 334-335). 
e culturais: a inexistência de uma metodologia e um regime jurídico próprios pode fazer com que possam ficar desprovidos de conteúdo, vigor e sentido.

Os direitos fundamentais sociais devem ser caracterizados, portanto, muito mais do que como direitos prestacionais, "gastos públicos" ou "deveres estatais" mas como direitos de resposta ou, em outras palavras, direitos em resposta à questão social (SERAU JR., 2009).

Os direitos fundamentais sociais, segundo Segovia (2004, p. 47), constituem créditos do homem perante a sociedade. Amparam uma possibilidade ou garantem uma posição, geralmente futura, cuja realização não depende diretamente das potencialidades individuais. Dirigem-se, como não seria diverso, ao trabalhador, ao necessitado e ao indigente, ou seja, a todos que necessitam de auxílio. Tais direitos protegem, enfim, uma necessidade, uma carência; algo que não se possui, mas de que se necessita: a assistência social, a aposentadoria digna, o salário mínimo, o descanso, a habitação. ${ }^{7}$

Em que pese a plataforma ideológica neoliberal pretender reduzir ou acabar com os esquemas tradicionais de proteção social coletivos, verifica-se ictu oculi a inadequação disso. As pessoas possuem suas necessidades vitais e o Estado e os demais agentes sociais (por vezes coordenados por ele, ou financiando as políticas públicas) possuem função supletiva ou muitas vezes promotora, em relação a elas. A questão social muitas vezes é tão intensa que não se pode aceitar deixar larga parcela da população padecendo à livre mercê do mercado, com acentuado déficit em sua dignidade pessoal.

Quando a própria sociedade dá conta das contingências sociais, ou quando não as produz, adotando modelos político-econômicos mais justos, não há que se reclamar posições jurídicas (gerindo políticas e serviços públicos ou simplesmente determinando e regulamentando as ações dos componentes sociais). Todavia, quando o risco social extrapola as capacidades e competências da própria sociedade (o que acontece muito em virtude do sistema capitalista de produção econômica, por essência e natureza excludente) não se pode adotar um modelo jurídico-constitucional que não preveja instituições de atuação em defesa da dignidade humana.

Inafastável, dentro dessa linha de raciocínio, a necessidade de que exista uma efetiva rede de proteção social, coordenando, portanto, a resposta às demandas sociais. Afinal todos os cidadãos, independentemente de sua condição econômica, estão sujeitos às contingências sociais. ${ }^{8}$

7 COMPARATO (2005, p. 64) segue esse mesma senda de que os direitos sociais, em virtude do principio da solidariedade, correspondem à transposição, para o plano da sociedade política, da obligatio in solidum do Direito Privado Romano, consistindo, ademais, em políticas públicas de amparo e proteção social aos mais fracos e pobres, isto é, aqueles que sozinhos não possuem condições de viver dignamente.

8 Essa condição dos direitos fundamentais sociais como direitos de resposta às demandas sociais é encontrada em boa parte da doutrina que lhe dedicou atenção, ainda que implicitamente. Para Ana Olsen, "os direitos fundamentais sociais decorrem da busca do atendimento das necessidades humanas, eles correspondem a 
A essência dos direitos sociais é o atendimento adequado àquelas demandas coletivas e sociais, independentemente da realização de gastos públicos ou atividades estatais.

A vocação dos direitos humanos, para além das estruturas de seu berço burguês, tem mais a ver, portanto, com sua função do que com seu conteúdo. E sua função é, essencialmente, assegurar liberdade igual para todos (GRIMM, 2006, p. 103-105). ${ }^{9}$

O reconhecimento desta qualidade-função dos direitos fundamentais sociais permitiria, a nosso ver, a superação desse quadro de "insuficiência" teórico-constitucional, altamente danoso para sua eficácia e permissivo de elevados índices de exclusão social e indignidade em nossa sociedade.

\section{Conclusão}

Bobbio possui famosa passagem em que diz que hoje o problema dos direitos humanos não é mais filosófico, mas de concreção (1992). Entretanto, uma teoria mais robusta para os direitos fundamentais sociais seria mais proveitosa para sua implementação e concretização plenas.

Uma abordagem científica mais rigorosa a respeito dos direitos fundamentais sociais talvez pudesse auxiliar aqueles que operam nessa seara a ter mais força na defesa desses aspectos da dignidade humana. Como dissemos, simplesmente equiparar os direitos sociais a prestações estatais permite refluxos em sua proteção e eficácia, pois dá margem à argumentação de que os direitos sociais implicam elevados custos econômicos ao Poder Público, permitindo sua diminuição ou mesmo supressão (ainda que implícita).

A abordagem e a percepção dos direitos fundamentais sociais como permeantes de toda a sociedade tornaria-os mais defensáveis e menos elimináveis por

imperativos da dignidade". E, por isso, "deveriam ser satisfeitos independentemente da provisão do mercado" (2008, p. 311). No mesmo sentido, Plauto Fáraco de Azevedo diz que os direitos sociais são "garantia da humana sobrevivência ao abrigo da necessidade" (1999, p. 128). Jorge Miranda também segue essa senda. Para ele, "nos direitos sociais, parte-se da verificação da existência de desigualdades e de situações de necessidade - umas derivadas das condições físicas e mentais das próprias pessoas, outras derivadas de condicionalismos exógenos (económicos, sociais, geográficos, etc.) - e da vontade de as vencer para estabelecer uma relação solidária entre todos os membros da mesma comunidade política" (MIRANDA, 2000, p. 104). Uma interessante ótica é trazida por Zagrebelsky, que distingue os direitos fundamentais a partir de uma perspectiva de serem eles voltados à consecução de liberdades ou de conteúdos materiais de justiça. Segundo esse autor, portanto, os direitos fundamentais seriam "direitos de liberdade" - caso dos direitos fundamentais de primeira dimensão - ou, em contraposição, "direitos de justiça" - caso dos direitos sociais (2005, p. 75-92).

9 Segundo Grimm, o redescobrimento do componente jurídico-objetivo dos direitos fundamentais se deve justamente à refutação de suas premissas liberais, em particular aquelas que ensejam que a liberdade juridicamente igual (ou igualdade formal), sem intervenção estatal, conduz automaticamente à prosperidade e à justiça (2006, p. 161). 
discursos econômicos de ocasião e pouco preocupados com a cidadania e a questão da dignidade humana.

No mesmo sentido poderia ser vivenciada uma melhor judicialização ou exigibilidade judicial dos direitos fundamentais sociais, buscando-se uma tutela judicial diferenciada (BEDAQUE, 2003), à medida que um aprofundamento teórico a esse respeito propiciaria melhores caminhos aos operadores jurídicos que enfrentam as contendas judiciais sociais.

Nestas bases, acreditamos que este breve trabalho tenha cumprido seu despretensioso papel, tentando apontar alguns problemas teórico-conceituais relativos aos direitos fundamentais sociais com vistas a assegurar sua plena efetividade.

São Paulo, outubro de 2010.

Referências

AZEVEDO, Plauto Faraco de. Direito, justiça social e neoliberalismo. São Paulo: Revista dos Tribunais, 1999.

BEDAQUE, José Roberto dos Santos. Direito e processo: influência do direito material sobre o processo. 3. ed., rev. e ampl. São Paulo: Malheiros, 2003.

BOBBIO, Norberto. A era dos direitos. Tradução de Carlos Nelson Coutinho. 18. tir. Rio de Janeiro: Campus, 1992.

BONAVIDES, Paulo. Curso de direito constitucional. 13. ed., rev. e atual. São Paulo: Malheiros, 2003.

CANÇADO TRINDADE. Antônio Augusto. Tratado de direito internacional dos direitos humanos. 2. ed., rev. e atual. Porto Alegre: Sergio Antonio Fabris Editor, 2003. v. 1.

CANOTILHO, J. J. Gomes. "Brancosos" e Interconstitucionalidade: itinerários dos discursos sobre a historicidade constitucional. Coimbra: Almedina, 2006.

CESARINO JUNIOR. A. F. Direito social brasileiro. 6. ed., ampl. e atual. São Paulo: Saraiva, 1970. v. 1 .

CORREIA, Marcus Orione Gonçalves; CORREIA, Érica Paula Barcha. Curso de direito da seguridade social. São Paulo: Saraiva, 2001.

COMPARATO, Fábio Konder. A afirmação histórica dos direitos humanos. 4. ed., rev. e atual. São Paulo: Saraiva, 2005.

FARIA, José Eduardo. Qual o futuro dos direitos: Estado, mercado e justiça na reestruturação capitalista. São Paulo: Max Limonad, 2002. 
GARCÍA DE ENTERRÍA, Eduardo. Justicia y seguridad juridica en un mundo de leyes desbocadas. Madrid: Civitas Ediciones, 2000.

GRIMM, Dieter. Constitucionalismo y derechos fundamentales. Tradução de Raúl Sanz Burgos y José Luis Muñoz de Baena Simón. Madrid: Trotta, 2006.

HESSE, Konrad. Elementos de direito constitucional da República Federal da Alemanha. Tradução Luís Afonso Heck. Porto Alegre: Sergio Fabris, 1998.

MIRANDA, Jorge. Manual de Direito Constitucional, Tomo IV - Direitos Fundamentais, 3 ed., rev. e atual. Coimbra: Coimbra Editora, 2000.

OLSEN, Ana Carolina Lopes. Direitos fundamentais sociais: efetividade frente à reserva do possível. Curitiba: Juruá, 2008.

SEGOVIA, Juan Fernando. Derechos humanos y constitucionalismo. Madrid: Marcial Pons, 2004.

SERAU JR, Marco Aurélio. Seguridade social como direito fundamental material. Curitiba: Juruá, 2009.

ZAGREBELSKY, Gustavo. El derecho dúctil. Madrid: Trotta, 1998. 